\title{
THE IMAGINED COMMUNITY REVISITED THROUGH A MOCK-NATIONALISTIC YOUTUBE WEB SERIES
}

Fernando Andacht Universidad de la República, Uruguay fernando.andacht@fic.edu.uy

\begin{abstract}
This paper is based on the question: can we revisit the notion of 'imagined community' (Anderson, 1983) to use it as a reliable analytical tool for media studies in the digital age? The concept is widely used in social sciences and media studies, but is used more often than not with total disregard for its epistemological purport, thus jeopardizing its heuristic value. I consider a concept initially proposed as a valuable approach to study the emergence of nations in the $19^{\text {th }}$ century, adapting it to analyze a popular parodic take on the $21^{\text {st }}$ century nation which takes YouTube as its medium. I argue that Anderson's 'imagined community' benefits from being redefined in terms of Peircean semiotics. My approach is based on Peirce's phaneroscopic categories, and on the iconic working of the human imagination. As a case study for this revisited concept, I use a YouTube weekly series called Tiranos Temblad, which consists of an odd medley of amateur
\end{abstract}

Digital Age in Semiotics \& Communication, Vol. I, No. 1, Spring 2018, Pp. 35-50 
videos drawn from that social media website. The topic of all these videos is a discussion of or reflection on the small Latin American nation of Uruguay. Some of the edited videos are local but many come from abroad. The latter enthusiastically praise Uruguay but lack even the most elementary knowledge about it, as the voice-over narrative never fails to remark and celebrate in a deadpan style that makes the series curiously funny. I claim that this web series is a parodical revisiting of nationalism and of the rebranding of a nation.

Keywords: imagined community; YouTube; Tiranos Temblad; post-nationalism; Peircean phaneroscopy

\section{The bountiful archive of YouTube as a digital Wunderkammer}

So much is talked about memory, because it does not exist any longer. (...) There are sites of memory, because there are no more environments of memory. (P. Nora, 1984, xvii) Just like in the disrespectful window display Of any pawnshop, life is all mixed up,

And wounded by a sword without rivets You can see the Bible crying next to a boiler (Cambalache, tango by Enrique Discépolo, 1934)

The notion of "imagined community" that Anderson (1983) posits to account for the emergence of modern nations in the 19th century makes use of ritually shared materials for reading and listening, such as newspapers and patriotic anthems. Nowadays, it includes audiovisual artifacts constantly created by anonymous individuals to be shared by an indeterminate number of viewers scattered throughout the planet, namely, homemade videos that their non-professional makers upload on the social network YouTube as soon as they film them. This bountiful audiovisual archive was called "a kind of digital Wunderkammer" (Gehl 2009: 45) which functions as a frame only, since "YouTube does not produce any content of its own, only the frame in which content appears; all of the content is provided by third parties" (Ibid.).

That kind of variegated audiovisual material is the raw material of Tiranos Temblad. Resumen de Acontecimientos Uruguayos ('Tyrants tremble! 
An overview of Uruguayan Events' - henceforth TT), a weekly YouTube series that was launched in December 2012 and distributed until October 2016. Besides being amateur productions, the feature all the video fragments share that make up each program is their having as an explicit theme or implied scenario everyday life in Uruguay, and an attitude about this country which oscillates between utter satisfaction and unrestrained euphoria. The sheer banality or the ridiculous nature of what is represented every week in the images of the collage edited in TT would seem a priori incompatible with the kind of emotion that was compared with "a secularized religion whose fully worked-out liturgy, symbols and mass actions (...) became integrated into the daily life of the people" (Elgenius 2005: 26). Besides the non-serious nature of the materials of TT, there is the odd tone used by the narrator, whose voice-over glosses every single clip, from the beginning to the end of each episode, which contributes to its comic effect, which I analyze below.

\subsection{YouTube as the launching site for a post-nationalist \& postdocu- mentary culture}

The hypothesis of the article is that the parodic style of TT is an expression of post-nationalism in the internet age, an ironic though not scornful revisiting of patriotism. In a similar sense to Corner's (2002) claim of our having entered a "post-documentary culture" on television, one which features prominently the reality show as a popular variation on the respected film genre that John Grierson (1933) baptized as "the creative treatment of actuality", I claim that we have entered a post-nationalistic and post-documentary culture whereof the YouTube series TT is emblematic. My claim does not amount to asserting the death of that powerful, widespread collective emotion; it is a reflection on the endless redefinition of politics as the distinctive discourse of citizens: "The logos politikos is not a single code or original text, but a creative process through which many speakers and audiences collaborate to invent ever more eloquent statements of who they are and what they should do" (Hariman 2008: 260).

But why should we study non-serious, „parodical“ signs, or the Uruguayan imagined community in the second decade of the 21 st century? To answer this query and verify my hypothesis, I propose a semiotic analysis of an alternative way to imagine the social realm, an identity ideology that is the upshot of new technological affordances. I use 'ideology' here not as that which, say, social constructionism aims to unmask (Hacking 1999), but rather as Mannheim's (1960/1936:52) definition, "the totality of the structure of the intellectual world belonging to a social group in a 
given historical situation". Taking a qualitative approach to the meaning of certain TT episodes, I study the signification process of what became a very popular phenomenon with many followers inside and outside the country. ${ }^{1}$ Concerning the artificiality of the technological devices with which the nation is imagined, I agree with Anderson (1983: 6): nations "are invented where they do not exist". Still, that does not make them inauthentic; a nation "is imagined because the members of even the smallest nation will never know most of their fellow-members, meet them, or even hear of them, yet in the minds of each lives the image of their communion" (Anderson 1983:6). For the invention of the national community to take place, there must be the cultivation of a style, the careful selection of material signs with which to imagine the limits and the collective identity of the people who dwell in it. Something akin to this process happens to people who do not belong to it, but who imagine a certain nation as an appealing place. That is precisely the main plot of every TT episode, the recurrent theme of that bizarre mishmash of mundane events. Its name is deceitful, since these are not media 'events', not in the sense discussed by Dayan and Katz (1994), in their study of "The live broadcasting of histo$r y$ ". In this study the authors analyze memorable occurrences such as royal weddings, a Pope's historic visit or the funeral of a powerful politician. The media representation of such moments creates worldwide interest for its high position in the news agenda; due to their impact on public opinion, they become historical landmarks. Those features are glaringly absent from the (mostly) domestic or amateurish art videos that the TT editor selects to construct this YouTube series. Nevertheless, the adjective 'Uruguayan' correctly describes the distinctive feature of the heterogeneous videos composing this audiovisual collage. Whether made by Uruguayans who live in the country or outside of it - a centripetal vision-or by foreigners who visit Uruguay or make a cognitive/imaginative journey through this small Latin American country - a centrifugal vision -, all the videos found on YouTube and organized for each episode's montage have as their single, explicit topic Uruguayan matters, be they geographical, cultural, political, musical, meteorological, sports, etc. A way to describe this uncanny creation is to picture an encounter or cross between a wickedly faulty Wikipedia, Ferdinand Cheval (1836 -1924), the creative, improvised builder of the Palais Idéal, and the reclusive artist of the eclectic shadow boxes Joseph Cornell (1903-1972). The two obscure creators became honorary members of the

\footnotetext{
${ }^{1}$ The average number of visitors of each episode of TT on YouTube is 100.000 . At the time of writing this article, the creator has not uploaded a new program for a year. The last one covers many months (17.03.16-25.10.16), and it is the 75th.
} 
surrealist canon, after their demise. Such is the exotic and bewildering nature of the audiovisual concoction for each episode of the YouTube series TT.

The series is a labor of love for a "new-fangled" curator to an imaginary, virtual museum of disposable artifacts from individual memory that, had it not been for their inclusion in the montage of $T T$, would have never been watched by the channel's very large audience, and would have had an altogether different meaning. The domestic videos undergo a noticeable change in their signification from being edited, glossed and classified in one of the regular sections of TT.

An important theoretical contribution to make sense of this non-commercial social media project is Nora's (1989) "sites of memory": "we have seen the tremendous dilation of our very mode of historical perception, which, with the help of the media, has substituted for a memory entwined in the intimacy of a collective heritage the ephemeral film of current event." Three decades later, the prescient verdict of this French historian has been confirmed through the endless proliferation of domestic personal videos distributed on websites such as YouTube. These signs work as a substitute for oral memory; they seek to create an iconic inventory of the social imaginary of our time.

\section{Towards a "new fangled" representation of one's cherished (?) na- tionhood}

To study these new "sites of memory" (Nora 1989), I analyze a new kind of Latin American media representation of sociocultural events that, due to their banal and frivolous nature, seem to be doomed to oblivion. Such is the fate of the constant filming of everyday life, the pervasive cultural practice aiming to obsessively preserve individual memories, and to share and socialize them on social media. This habit endows trivial video material with a potential for becoming a collective memory, which modifies its overt mundane, ephemeral character. The act of recording the everyday in all its shapes involves an operation of "metacommunicational" framing (Bateson 1972: 179; Goffman 1986, passim), namely, the act of transforming videos of almost all moments of everyday life into the kind of occurrence that no longer coincides with a ceremony, such as a wedding or a holiday trip. Normally, their life cycle is short and it addresses a small audience, for instance when a video is shared with family and friends through WhatsApp or on someone's Facebook page.

But it is becoming increasingly common to take a further representational step: to share the domestic video on social media, notably YouTube, 
not before giving it a title. This current avatar of the home movie ${ }^{2}$ changes its tiny family audience to a wide, global spectatorship. The cultural practice of sharing what is private or intimate with a massive audience without clear limits entails a second framing act. The choice of $T T$ as an object of study is due to its interesting narrative strategy of scavenging through hundreds of YouTube videos and then re-signifying that framing operation of everyday experience. The videos then undergo a third keying (Goffman 1986: 44-45), namely, "the set of conventions by which (...) an already meaningful primary framework is transformed (and) seen by its participants to be quite something else". The variegated episodes (of lengths varying from 10 to 12 minutes) compose an odd virtual artifact of memory that is neither individual nor social; through its unconventional montage TT has become part of the virtual heritage of a Latin American nation. This is not only due to the selection of videos about Uruguay, but also the painstaking curatorial effort of organizing the material that goes into the making of each episode. To use the terms of Kermode (1967: 46), what takes place through this elaborate montage may be described as the radical transformation of clear instances of chronos - the kind of unremarkable temporality that is soon forgotten - into a modest instance of kairos -the kind of time that is most significant, those special moments we redeem from oblivion, so they remain in our memory. Through their special status, such memorable occasions shape our lives.

In what follows, I will approach the transformation of overtly banal videos, which deserve to be forgotten almost as soon as they were made, (the caught filming of a relative, silly chance observations) into a "new-fangled“ form of neo- or post-nationalism. This effect is attained through the use of parody and irony, which are found not only in the comments of the narrator-cum-curator of $T T$, but most remarkably in the monotonous, deadpan tone he uses during the entire length of each program. Thus TT may be construed as an imaginary museum of the short-lived but revealing memory of the cultural practices of an imagined community of Latin America, in the second decade of the $21^{\text {st }}$ century. For my take of this media phenomenon, I will use both Benedict Anderson's account of the genesis of $19^{\text {th }}$ century nationalism and C. S. Peirce's semiotic model.

\subsection{When the social imaginary is built in the shape of a chaotic pawn- shop}

Elsewhere (Andacht 2001), I have studied the tiny verbal and visual rectangle of the postage stamp as a privileged semiotic window to the ideol-

\footnotetext{
2 We could consider Le repas de bébé (1895) by the Lumière Brothers as the oldest antecedent of this domestic film genre.
} 
ogy underlying the nation whose name that sign proudly exhibits, to its social imaginary. Although Anderson (1983) does not mention the stamp as one of the artifacts used for the invention of the modern nation, it is also part of "this extraordinary mass ceremony" (Anderson 1983: 35) of contemplating a shared identity sign. Writing about the effect of the collective consumption of newspapers ("one-day bestsellers"), Anderson (1983: 42) claims that "The idea of a sociological organism moving calendrically through homogeneous, empty time is a precise analogue of the idea of the nation", a similar temporality functions in the viewing of each episode of $T T$ construed as a one-week viral video. The relevance of this kind of material representation is justified by Anderson's claim that "communities are to be distinguished, not by their falsity/genuineness, but by the style in which they are imagined" (Anderson 1983: 6).

If someone with no knowledge of Uruguayan culture watched a typical TT episode, what that neophyte viewer would find most remarkable would be the promiscuous mixture of video fragments. Although there is an underlying order in the apparent audiovisual turbulence, the deadpan style of the voice-over narration is bound to perplex the newcomer: "two brothers read a book on dinosaurs; an aunt recited (a poem by Uruguayan poet) Juana de Ibarbourou; a dog which is seen barking had a dream; a group of masked Quinceañeras danced; a group of men carried bricks" (TT \#70). The eccentric prologue is followed by euphoric images of young female tourists seen wandering the Uruguayan countryside; of a young woman doing an appreciative "little dance" as an homage to the country, also in the heartland; then a Japanese and a German advertisement selling soft drinks made with or using the name 'mate' - the traditional Uruguayan herbal beverage - in their label; a group of wildly ill-matched inventions that juxtaposes funny-looking home-made devices with the engineering design of an eccentric inventor. Without any transition there ensues a parade of "a dog who remains perfectly still on a dock (which we are told has already been featured on TT); a man who taught how to make a home repellent". The incongruous group of edited video fragments creates the impression that the average TT episode - between 7 and 14 minutes - is much longer than what it actually is. The closure of this episode is brought about but one last deadpan styled comment: "And we leave you with the what-the-fuck ${ }^{3}$ moments of the week: "the armadillo cat, this hand that was swallowing the clouds along the highway."

${ }^{3}$ In English, in the original; it uses a video of a Uruguayan adolescent who cheerfully uses that expletive. 
It is fitting to describe the disorderly collage of $T T$ with the rhetorical figure of the "chaotic enumeration". Spitzer (1945) uses this trope in his study of the poetry of Walt Whitman, which "violently brings close together the most disparate things, the most exotic and the most familiar, the gigantic and the minuscule, nature and the products of human civilization as a child who were leafing through the catalogue of a large store" (p. 26). To borrow a musical landmark of this region's popular culture, I compare the anarchic audiovisual catalogue portrayed by TT with the tango Cambalache by Enrique Discépolo, ${ }^{4}$ first performed in 1934 (Andacht, 1996). Its lyrics describe the staggering chaos of modernity epitomized by the "trouble-ridden and feverish 20th century". Besides violating the relevance principle of any imaginable TV news both in its composition and its very name - the parodic use of 'events' - the list of dull mundane occurrences selected each week overtly disregards the 'tellability' of Labov \& Waletzky' (1967) narrative model, the criterion which makes a story worth being narrated in conversation: "what happened and why it is worth telling" (Bruner 1991:12). The odd, counter-narrative of TT celebrates the 21st century iconic cambalache, namely, the hectic deluge of images and sounds constantly uploaded to that boundless archive YouTube.

Directly after the avalanche of trivial Uruguayan occurrences placed at the beginning of the episode, comes a ritual phrase uttered with resigned boredom - "Another week in Uruguay" - and the regular sections of TT ensue. The voice-over keeps using indefinite articles and pronouns ( $a$ young woman, a couple, $a$ singer, some men), as an entomologist who watched a garden from afar. However, gradually there is more specificity as some proper nouns drawn from the original title of each video-visible in the lower right corner - are used in the montage. A key ingredient of a verbal parody is the textual repetition of what somebody else said (Rossen-Knill \& Henry 1997:723); this juxtaposes the parodied style together with the parodying style. Another is the transposition of the fragment in a collage, which furnishes a wholly different context from the one that was designed for the mocked video. The hybrid resulting from the combination of the quoted video, the verbal gloss, and the new context provided by TT creates the comical effect of the series.

These are the categories or regular sections of each episode which bear a visible title: ENIGMA; UNCOMFORTABLE MOMENT; OHHHH MOMENT, and CRACK5. They are all followed by the English phrase: "OF

\footnotetext{
${ }^{4}$ A'cambalache' is a pawnshop, a place which typically exhibits a chaotic accumulation of things in its windows.

5 'Crack'is used as a noun; it refers to an outstanding athlete, or by extension to anyone who does something remarkable.
} 
THE WEEK", but when he says it, the narrator always talks in Spanish ("de la semana"). The choice of the English printed sign alludes ironically to the globalized world which tiny Uruguay entered timidly from its peripheral position. The song that celebrates the apotheosis of the weekly CRACK, which is joined in an ungainly and solemn manner by the commentator, is also performed in Spanish. There is also a sui generis section that does not classify a single type of videos or have a descriptive title; the "what the fuck moments of the week" section comes at the end of every episode. If one searched for the distinctive feature of all that is shown and narrated in $T T$, for its core ideology, 'banal' would fit the bill.

I will now look more closely at the category that sets the dull climax of the program, its purpose being to commemorate a prowess or its very opposite. A ritual phrase introduces viewers to CRACK of the Week: "And the nominees for the Crack de la semana are..." The list of those deserving such a prize is one further instance of chaotic enumeration to comedic effect, as it includes animate beings - humans and animals - as well as inanimate ones. These are some of the candidates: "an excavator which served water in a mate"; "these jumping worms which came out of a red bell pepper" (TT \#70); "the chair (called) Jessie" manufactured in Uruguay, whose video shows that this piece of furniture resists any kind of assault without breaking down ( $T T \# 21$ ). It is not unusual for the narrator to violate without any explanation the apparent criterion that defines a category, for instance the alleged virtue or exceptionality of him, her or the thing that deserves to be celebrated as the CRACK of the week. Thus we watch the big effort that a group of young women make in order to move a large sofa through a window, and once the deed is accomplished, the narrator determines that the person who is to be awarded the prize, which is both visual (two Golden cups resembling those of the soccer World Cup, Fig. 1) and musical, is the only one who had not joined the hard-working group, but who ran as fast as she could to be the first one to sit on the sofa (TT\#35).

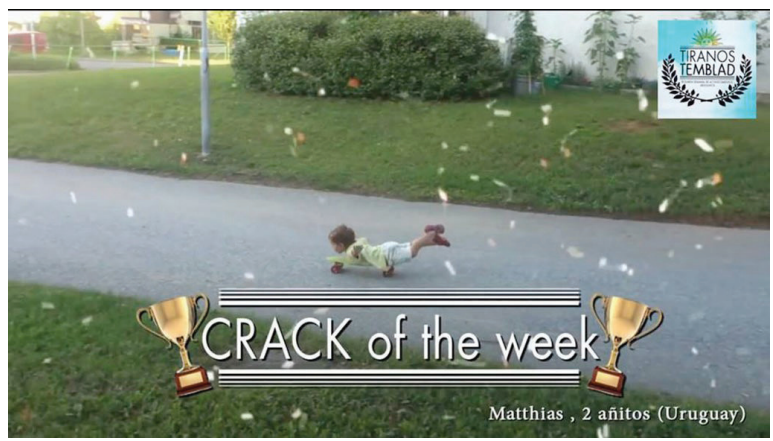

Figure 1. Two Golden cups resembling those of the soccer World Cup 
On other occasions, several nominees are crowned simultaneously for their efforts, whether successful or not, instead of honoring, as expected, a solitary champion. This paradox works particularly well in this nation: Uruguay still cherishes the memory of its irretrievable sporting glory, namely the legendary victory of their national soccer team against Brazil in the 1950 World Cup final. The decision to crown several people instead of just one, or the gesture of celebrating an anti-prowess, is a parody of the always yearned for but unreachable world victory in that sport, a part of their national identity. Although the improbable sport victory of the tiny David versus the regional Goliath is not likely not happen again (Andacht 2002), the cherished memory is deeply rooted in the Uruguayan imagined community.

\section{Peircean phaneroscopic categories to analyze the categories of $T T$}

To analyze the realm of nationalism that is an imagined community, I will use Peirce's theoretical model, and the phenomenological categories that form the basis of the many-hued, multi-functional sign process or semiosis. The simplest valency found in his analysis of experience is Firstness, an absolute, possibilist qualitative element; Secondness pertains to all that exists, reacts, resists and thus affects our perception; Thirdness characterizes the process of representation, which involves a purpose, whether we are aware of it or not (CP 1.532) $)^{6}$. And the categories apply recursively to themselves. I propose to analyze the collective imagination that engenders the modern nation as "the Firstness of Thirdness, the peculiar flavor or color of mediation" (CP 1.533). To analyze the ideology that is staged in each and every parodic episode of TT, I will use the term 'Mentality' (CP 1.533.), which Peirce proposes to describe the qualitative dimension of any law or regularity, such as nationalism, the ideology that in an ironical key tinges the entire chaotic collage of this YouTube series.

The first part of the program's name is sure to puzzle a foreigner, but not a Uruguayan, even less one that lived in the country during the hard, leaden years of the military dictatorship (1973-1985), as the writer of this text did. The phrase "Tyrants tremble!" belongs to the refrain of the national anthem, one of the semiotic artifacts to which Anderson (1983) attributes the power of creating the imagined community, and, I would like to add, the nationalistic ideology or 'Mentality'. During the dictatorial regime, on holidays, when the anthem was performed in public places such as a cin-

\footnotetext{
${ }^{6}$ I use the conventional way of quoting the work of Peirce: $x . x x x$ is a reference to the volume and paragraph of The Collected Papers of C. S. Peirce (1931-1958).
} 
ema, only that portion of its lyrics was shouted vehemently, rather than sung, with the unequivocal aim of repudiating the dictatorship, which brutally suppressed any form of explicit opposition.

With its deadpan tone, $T T$ parodically revisits that sentiment of stifled rebellion, and transforms it in an ironic smile that resignifies the very notion of nationalism and political involvement in peaceful times, in the age of social media. The program has a Mentality or flavor of mediation that is utterly different from that which prevailed during the time of State terrorism. It is not by chance that besides having borrowed that eloquent fragment of the nation's liturgical song, the opening image of TT is a playful icon of the flag, wherein the heraldic image of the sun, with its geometrical, flaming figure, is set upon the name of the series (Fig. 2), as if the national emblem sponsored it.

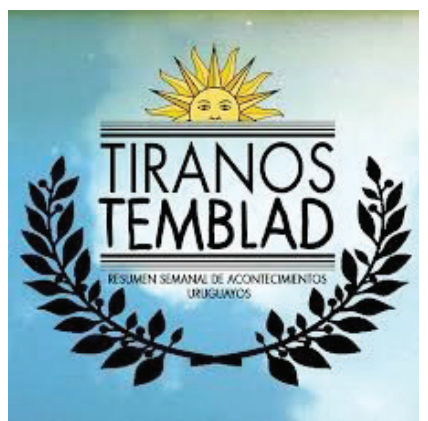

Figure 2. The logo of the series

Although most of the edited videos that make up TT show anonymous people doing banal things, every once in a while, a celebrity makes an appearance in that chaotic arrangement. When this happens, the famous one is not represented as such, in a glorifying performance, but in a rather oblique way, for instance, in an amateur shaky video, and he is portrayed doing something strange, wholly unrelated to the celebrity's aura. Such is the case of a video of rock musician Steven Tyler made while he was on tour with his group, Aerosmith, in Uruguay. We learn that "after he played for thousands of people, he ended up digging into a garbage container in the Old Town" (TT \# 35). The climax of the video narrative arrives with a comment that makes explicit what I claim to be the central meaning of this series: "He arrived as a star and he leaves as a humble person". Thus, the narrator makes a parody of the proverbial Uruguayan humbleness, its negative arrogance, namely, boasting about not boasting about the supposed national virtues as a key ingredient of Uruguayan mesocratic social imag- 
inary. This is a Mentality that takes pride in not being proud of its nation, and in the love of middle-class ideals, and most of all in not trying to be outstanding, a defining feature of the nation's collective identity (Andacht 2002). On this point, it should be mentioned that at no time do we see the narrator.

\section{Concluding signs: the semiotic virtual antidote to nationalism Ti- ranos Temblad}

The quoted remark of that episode of TT ends with a musical scene that is part of almost every program; it is the song Uruguay composed by Russian violinist Aleksey Igudesman. The video shows the artist playing while accompanied by a youth symphonic orchestra of Austria, as he sings exuberantly with a heavily accented Spanish, in a manner that borders ridicule: "Uruguay is the best country, better than France and better than Paris!" With his unaltered deadpan tone, the narrator of TT says that the bizarre behavior of rock musician S. Tyler - which was classified as the "ENIGMA of the week"-is "a further evidence that" and then comes the end of the program with the musical quote that exalts this nation both excessively and with an unmistakable foreign element. Few expressions of praise can match that of humbleness in the imagined mesocratic realm: the strong desire to not be exceptional in any way, to be just one more modest member of the national collective unit that is represented as a key national virtue. As in a kind of contagion effect, this national trait has allegedly infected the American rock star in his first visit to the country. The ironical praise of the national ideology expressed through the leader of Aerosmith's supposed transformation into a mesocratic citizen is an example of the way in which "parody creates and sustains public consciousness first and foremost by exposing the limitations of dominant discourses: it counters idealization, mythic enchantment, and other forms of hegemony" (Hariman 2008: 253).

Based on the audiovisual material of the YouTube program TT, there is sufficient evidence to support the hypothesis of this text: the commented edition of quotes of miscellaneous, eccentric and overtly trivial videos, with their centripetal and centrifugal visions of the Uruguayan nation, generates as its central meaning post-nationalism, the ironic revisiting of patriotism in the age of social media. In Peirce's semiotic model, meaning corresponds to the interpretant component of the semiosis process, which is defined as "the mental effect, or thought" of the sign (CP 1.564). Far from being an unchanging element, as I have already stated about the evolving purport of political discourse, meaning is part of a logical metabolism inseparable from temporality: the sign "addresses somebody, that is, creates 
in the mind of that person an equivalent sign, or perhaps a more developed sign. That sign which it creates I call the interpretant of the first sign" (CP 2.228). To express it most succinctly, "symbols grow" (CP 2.302).

My claim is that the programs of $T T$ are interpretants of present-day national ideology in Uruguay; the numerous visits to this YouTube channel and the enthusiastic comments on TT episodes can be construed as acts of legitimation. The imagined community represented by TT is one of the forms through which the Latin American political collective imagines itself today. This article's aim has been to understand how these signs are generated, and identify their political consequences. TT's remarkable popularity coincided with a historical moment of surging prestige for Uruguay's nation brand. This was the outcome of a politician's popularity who was described by international media as "the world's poorest president" (José Mujica, 2010-2015), and of some laws which were passed during his term of office (e.g. the legalization of recreational marihuana). According to Kanarek (2015), this was mostly the work of quality news media such as The Guardian and The Economist. The parodic take on nationalism performed by TT could be understood as a defensive reaction to this threat to the traditional Mentality of this nation; thus a strange semiotic virtual antidote emerged to keep the time-honored limits of the imagined community, and of its hegemonic ideology, in a non-traditional manner. 


\section{References}

Andacht, Fernando. 2002. Integración/desintegración: nuevos signos de identidad en el Mercosur. In Gerónimo de Sierra (ed.) Los Rostros del Mercosur. El difícil camino de lo comercial a lo societal, 309-340. Buenos Aires: Clacso.

Andacht, Fernando. 2001. L'imaginaire d'un petit pays. Approche Sémiotique de l'identité sociale à travers des timbres postes. Protée 30 (2): 9-22.

Andacht, Fernando. 1996. Cambalache y creación: semiosis de la primeridad. Signa 5, 52-60.

Anderson, Benedict. 1983. Imagined communities. Reflections on the origin and spread of nationalism. London: Verso.

Bateson, Gregory. 1972. Steps to an Ecology of Mind: Collected Essays in Anthropology, Psychiatry, Evolution, and Epistemology. Chicago: University of Chicago Press.

Bruner, Jerome. 1991. The narrative construction of reality. Critical Inquiry 18: 1-21.

Corner, John. 2002. Performing the real. Documentary diversions. Television \& New Media 3 (3): 255-269.

Dayan, Daniel \& Katz, Elihu. 1994. Media Events. The Live Broadcasting of History. London: Harvard University Press.

Elgenius, Gabriella. 2005. Expressions of nationhood: national symbols and ceremonies in contemporary Europe, PhD Thesis, LSE Theses Online: http://etheses.1se.ac.uk/638/ Retirado: 05.02.2016.

Gabler, Neal. 1998. Life the movie. How entertainment conquered reality. New York: Vintage.

Gehl, Robert. 2009. YouTube as archive. Who will curate this digital Wunderkammer? International Journal of Cultural Studies, 12 (1), 41-60.

Goffman, Erving. 1986. Frame Analysis. An Essay on the Organization of Experience. Chicago: Northeastern University Press

Grierson, John. 1933. The documentary producer. Cinema Quarterly 2 (1): 7-9. 
Hacking, Ian. 1999. The social construction of what. Cambridge, Mass.: Harvard University Press.

Hariman, Robert. 2008. Political Parody and Public Culture. Quarterly Journal of Speech 94 (3): 247-272.

Kermode, Frank. 1967. The Sense of an Ending: Studies in the Theory of Fiction. New York: Oxford University Press.

Kanarek, Julián. 2015. For export del Uruguay. Representación, resignificación e imaginario social de un país pequeño en medios de prensa del mundo. Tesis de Maestría en Comunicación, Universidad Católica del Uruguay, Montevideo.

Labov, William \& Waletzky, Joshua. 1967. Narrative Analysis: Oral versions of personal experience. In John Helm (ed.) Essays on verbal and visual arts. 12-44. Seattle: University of Washington.

Mannheim, Karl. 1960/1936. Ideology and Utopia. London: Routledge \& Kegan Paul.

Naficy, Hamid. 2001. An Accented Cinema: Exilic and Diasporic Filmmaking. Princeton, N.J.: Princeton University Press

Nora, Pierre. 1989. Between memory and history: Les Lieux de Mémoire. Representations 26: 7-24.

Peirce, Charles Sanders. 1931-1958. The Collected Papers of C. S. Peirce. Charles Hartshorne, Paul Weiss \& Arthur Burks (eds.). Cambridge, MA: Harvard University Press.

Pereyra, Gabriel. 2013. Interview to Agustín Ferrando. Television program Enla Mira (27.04.2013): https://www.youtube.com/watch?v=GA9ARpaueNI

Rossen-Knill, Deborah \& Henry, Richard. 1997. The Pragmatics of Verbal Parody. Journal of Pragmatics 27: 719-752.

Spitzer, Leo. 1945. La enumeración caótica en la poesía moderna. Translated by Raimundo Lida. Buenos Aires: Facultad de Filosofía y Letras. Instituto de Filología/Casa Coni. 
Full references of the cited weekly episodes of Tiranos Temblad. Resumen de Acontecimientos Uruguayos (referred to as TT):

TT \# 21 (05/12/2013 to 06/01/2013) https://www.youtube.com/ watch? $=4$ _jFflmtDc8

TT \# 35 (10/06/2013 to 10/12/13) https://www.youtube.com/ watch? $\mathrm{v}=\mathrm{kPPS} 93 \mathrm{dyF} 6 \mathrm{Y}$

TT \# 70 (08/03/2015 to 08/23/2015) https://www.youtube.com/ watch? $=$ riU7JzkQhAc 